\title{
Medical Actions Resulting in Malpractice in the Perspective of Indonesian Criminal Law
}

\author{
Ni Wayan Ika Siwi Sasanthi \\ \{siwisasanthi89@gmail.com\} \\ Magister of Law, Universitas Mataram, Nusa Tenggara Barat-Indonesia
}

\begin{abstract}
Basically in a medical case, there are two very fundamental problems: First, the one that comes from the patient or family of patients who do not understand about medical actions or procedures that sometimes pose medical risks; Second, the one that arises from doctors who are less communicative and do not provide a clear explanation of the disease or doctor's actions which then adversely affects the patient. This study examines malpractice in medical actions that are threatened and prohibited under criminal law as well as explores the forms of criminal liabilities for its execution. I applied the normative legal research method while utilizing the statute approach and conceptual approach. The results of data analysis show that malpractice occurs in various forms. Every type of malpractice has legal sanctions that cannot be prevented. There is a need of law amendment.
\end{abstract}

Keywords: Criminal law; malpractice; medical action

\section{Introduction}

In Indonesia malpractice is not a new case. Since two decades have been passing, this form of case has become familiar to the ears of the Indonesian people. Not only that has it been familiar to Indonesian, more importantly, malpractice has been brought on a good deal of talk among scholars and researchers during a couple of recent decades [1, 2, 3, 4, 5, 6, 7]. Basically, malpractice is the action of professionals who are in conflict with the Standard Operating Procedure (SOP), code of conduct, and the applicable Law, both intentionally and as a result of negligence resulting in loss and death of other people [8]. Malpractice is commonly carried out by doctors as result of negligence in diagnosing patients that ultimately causes the them to give the inappropriate medication [9]. This phenomenon is identical to what was experienced by a patient who lost his wife on December 19, 2003 at Rumah Sakit Cipto Mangukusumo in Jakarta, Indonesia. The husband of the patient Syafri, a resident of Central Jakarta, questioned the medical treatment given by a team of doctors to his wife at a number of different hospitals within two months. Among the different diagnostic actions, according to Syafri's attorney from the Jakarta Legal Aid Institute, patients experienced intestinal injuries, cysts, uterine tumors, and myoma. The patient's suffering started from the condition of vomiting blood; and thus various doctors from different hospitals have diagnosed it with different results. Tragically, the patient exhaled due to the installation of an intravenous syringe on the right neck. Installation of infusion itself is carried out by medical personnel who have not managed to find the arteries in the hand of patient in question [10].

In general, criminal acts of malpractice have actually been included in the provisions of the Indonesian Criminal Code, e.g. abortion without medical reasons and contrary to Article 
347 of the Criminal Code; divulge kedokteran secrets can be convicted by Article 322 of the Criminal Code; and euthanasia violates Article 344 of the Criminal Code. Meanwhile, Law No. 23 of 1992 concerning Health, in Article 54 paragraph (1), provisions concerning malpractice issues have also been regulated, but the contents in the Article stating "towards health professional who make mistakes or negligence in carrying out their profession may be subject to disciplinary action". At the sound of Article 54 paragraph (1) it is not explained what the purpose of the Article is so that the criteria referred to are not clear. In addition, the norm in this Article is no longer valid since the enactment of Article 85 of Law No. 29 of 2004 concerning Medical Practice.

At present society can only make their hopes on that Law No. 29 of 2009 concerning Medical Practice will clearly stipulate the medical malpractice. Unfortunately, it turns out that in Article 66, the material only regulates the internal disciplinary issues. Even though everyone can submit an objection to the Medical Disciplinary Assembly, only matters relating to the discipline component can be followed up. Meanwhile, for the legal aspect, the regulation refers to the Criminal Code if a crime occurs. Thus, if in this case the action constitutes negligence resulting in suffering or even causing casualties, the legal regulations are set forth in Article 359 of the Criminal Code. Conversely, if the human life is threatened by negligence, it can be threatened with Article 360 of the Criminal Code. Eradication of malpractice in the form of imposition of criminal sanctions can also be applied to every doctor who has proven guilty, as stipulated in Article 361 of the Criminal Code.

The clarification provided above is insufficient to provide adequate knowledge about the contents of the meaning of malpractice. As a result, if one time health service users experience malpractice, they do not know which types of malpractice are threatened and prohibited by criminal law and which are not, guiding them to file complaints with the authorities to obtain protection and welfare when time of malpractice experienced by them. Of course, if the community still has taken all this well, they can only remain calm and receive loss of life without the benefit of services from the perpetrators. And, as revealed out by [11], there had been 16 doctors out of defendants lost their trials in Taiwan throught out 4 years. Such evidence should not be allowed to continue in order to fully provide real health services for the community.

Apart from all that, what needs to be cognized is the criminal liability that shall be undertaken by the perpetrators of the malpractice, because in the view of law if the victims is in need of making complaints to the authorities, they are required to provide any proofs or at least to show that the act is real a malpractice. Unfortunately, as mentioned earlier, in the Indonesian Legislation Regulations there are no detailed and clear arrangements regarding the medical malpractice. Therefore, so far the regulation regarding malpractice is still of a vague status of norm. This is proven by Law No. 23 of 1992 concerning Health Article 54 paragraph (1) which regulates malpractice issues but does not provide a comprehensive explanation of malpractice and its substance, so the criteria need to be questioned, as well as Law No. 29 of 2004 concerning Medical Practice in Article 66 which regulates malpractice only at the level of internal disciplinary issues. This condition provides a big advantage in the form of the absence of legal regulations that strictly regulate the rights and obligations (gray of norms), including the liabilities for every wrong action the health professionals commit. Pragmatically, in such a situation health professionals seems to be considered immune in the real context of law.

The study tries to bridge the community (patient) to the clear awareness of the types of medical actions that are against the law and threatened by the law itself. In this effort, this study also tries to reveal what types and forms of criminal responsibility to be imposed to the 
health professionals at times they are proven to have made a mistake in providing medical treatment services to patients.

To realize the efforts of achieving the objectives of our study, we used normative legal research design, e.g. we conducted analysis by referring to the related literature and legislation that to malpractice actions and to the forms of their criminal liabilities. There are several types and data sources that we use in this study, namely (1) primary legal material: binding legal material, such as the Criminal Code, Law No. 23 of 1992 concerning Health, Law No. 36 of 2009 concerning Health, Law No. 29 of 2004 concerning Medical Practice, regulation of Health Minister of the Republic of Indonesia No. 290 of 2008 concerning Approval of Medical Action, Republic of Indonesia Government Regulation No. 32 of 2009 concerning Health Workers; (2) secondary legal material: legal material that provides an explanation of primary legal material, such as the doctrine relating to medical and malpractice actions; (3) tertiary legal material: legal material that provides guidance or explanation of primary legal material and secondary legal material, such as language dictionaries and Indonesian legal dictionaries [12]. We made use of documentation technique in collecting data of this study. We collected books that discuss the Law on public health services, medical actions, and malpractice. We analyzed the data with qualitative data analysis technique. We processed the legal sources and analyzed them by starting from general matters and then looking for the main elements relating to medical actions and malpractice and then were connected with the Laws and Regulations relating to the problem of medical action and malpractice, such as Law No. 23 of 1992 on Health, Law No. 29 of 2004 concerning Medical Practice, Indonesia Health Ministry Regulation No. 290 of 2008 concerning Approval of Medical Action, Indonesia Government Regulation No. 32 of 2009 concerning Health Workers, and the applicable Penal Code. The last activity was drawing on conclusions.

\section{Results and Discussion}

\subsection{Criminal Law-Based Threatened and Prohibited Medical Action}

Initially malpractice arises from medical actions carried out in an inappropriate or contrary manner to medical service standards [13]. As explained earlier, what is meant by medical service standards based on Indonesian Health Minister Regulation No. 585/MEN.KES/PER/IX/1989, as amended to become Regulation of the Minister of Health of Indonesia No. 290/MEN.KES / PER/III/2008, is a preventive, diagnostic, therapeutic, or rehabilitative medical action performed by a doctor or dentist on his patients. In addition, medical action is an action that should only be carried out by medical personnel, because the action is intended primarily for patients who experience typical health problems [14].

Sutorious determines 5 elements for medical action, namely:

a. The performer of medical action must be certified doctors;

b. The patient should be given adequate information related to the medical actions and approval of medical action to be taken to him must be obtained;

c. There must be medical indications which are the starting point of all subsequent medical actions;

d. The doctor must be able to formulate the goals of giving the treatment, besides having to also consider other alternatives chosen;

e. All actions must always be directed towards the welfare of his patients [15]. 
Medical actions must be performed by medical personnel. In Indonesian positive law, e.g. in Indonesia Government Regulation No. 32 of 1996 concerning Health Workers which is the Implementing Regulation of Law No. 23 of 1992 concerning Health, it is distinguished between medical personnel and health workers, in that what is meant by health workers is any person who is devoted to the health sector and has the knowledge and/or skills through education in the health sector which requires certain types of efforts health. Meanwhile, medical personnel are those whose profession is in the medical field, which includes doctors, both physical doctors and dentists.

An action of medical treatment must not only be in accordance with medical standards, but must be aimed at a goal of medical science. The objectives of medical science include:

a. To cure and prevent disease medically: a treatment must meet the ability criteria to cure and prevent the continuing process of an illness. A therapeutic action that when viewed from the medical side turns out to not produce results, it should not be performed or even though treatment measures have begun, basically it must be stopped. If continued, the action will only prolong the process of death. The aim of medical science is not just to try to extend life as it is, but a quality life.

b. To relieve the suffering: one of the traditional goals of treatment is to alleviate suffering. In addition to alleviating the feeling of uneasiness or pain caused by the process of the disease, the medical action is also to avoid the suffering that might arise as a result of doing medical actions, both in doing therapy and in order to make a diagnosis.

c. To accompany the patients and alleviate their suffering is the duty of the same doctor in accordance with technical expertise to treat the disease. Therefore, doctors must provide the same time for these activities. Medical science does not limit itself to biological aspects, but a holistic approach to seeing patients as whole people is part of real medical science. In a critical situation, the doctor is obliged to make sure that the patient is accompanied by his family and relatives.

In essence, in every medical action, there will be a relationship between doctors and patients, which in relation to medical science the relationship takes place as an active-passive biomedical relationship. Only in this relationship can there be an imbalance between doctors and patients, e.g. what is seen is the superiority of doctors who provide medical services to patients.

Indeed, the basic pattern of the relationship between doctors and patients is primarily based on the social, cultural and disease conditions of patients, where the relationship can be distinguished in three patterns, namely:

a. Activity-Passivity: The pattern of parent-child relations is a classic pattern since the medical profession began to recognize the code of ethics in the 5 th century BC. Here the doctor seems to be able to fully apply his knowledge with an altruistic motivation without the patients' intervention. Usually, this relationship applies to patients whose safety is threatened, or is in unconscious condition, or suffering from a severe mental disorder.

b. Guidance-Corporation: This relationship guides collaboration, as do parents with teenagers. This pattern is determined if the patient's condition is not too heavy, for example a new infectious disease or other acute disease. Even though he/she is sick, the patient remains conscious and has his own feelings and will. The patients try to seek medical help and are willing to cooperate. Even though doctors know more, they are not merely exercising power, but expect collaboration from patients that is realized by following the advice and recommendation of the doctor. 
c. Mutual Participations: This philosophy is based on the idea that every human being has the same rights and dignity. This pattern occurs in those who maintain their health such as medical check-ups or in patients suffering from chronic diseases. The patient consciously participates in the treatment of himself. This applies to patients with low educational and social backgrounds and to children or patients with certain mental disorders [16].

The relationship between the doctor and the patient occurs through an agreement or contract. The relationship began to be formed with the question and answer between the doctor and the patient, which then continues with a physical examination and finally the doctor gives a diagnosis. Diagnosis performed at this stage is a temporary diagnosis or even a definitive diagnosis. After that, the doctor plans a follow-up action by prescribing drugs, injections, surgeries, or other actions deemed necessary.

Juridically, medical action is often disputed to determine whether it is included in the definition of persecution or not. However, if a medical action is carried out by not fulfilling the requirements, such as having a medical indication, carried out according to the applicable law, and having obtained the consent of the party concerned in this case the patient, it becomes very clear a form of persecution. Regarding the relationship between patients and doctors, basically it is an effort that is endeavored or done with maximum effort. The doctor does not promise a healing to the patient, but he must make every effort to cure the patient.

In the perspective of medicine, medical agreements can be elaborated through common efforts made by doctors in a form of health services or medical services. Health services can be started from apromotive, preventive, curative, and rehabilitative businesses, and thus variations of the object of medical agreement can be in the form of: (a) Medical check-up (b) Immunization (c) Family planning (d) Disease healing efforts (e) Relieve suffering (f) Life extending and (g) Rehabilitation.

If the doctor has carried out medical actions in accordance with the procedure or standard of the profession and there is no negligence, generally it will not cause legal problems. Therefore, one of the patients' efforts to avoid malpractice is by having informed consent for each action and medical service for the patient. This is very necessary to protect patients from the arbitrariness of health workers. Informed consent is provided by the patient or the patient's family to the doctor to take medical action in accordance with what was explained by the doctor beforehand.

In Article 1 number 1 Regulation of the Minister of Health No. 290 of 2008 concerning Medical Action Consent states that the approval of medical action is the consent provided by the patient or the closest family after obtaining a complete explanation of the provide of medicine or dentistry to be performed on the patient. The doctor is liable in providing clear information and seek consent from the patient to take a medical action. However, if the patient cannot be invited to communicate about it, say the patient is unconscious, the doctor asks for approval from the patient's family. In providing information, doctors must explain using language that is easily understood by patients and their families. If the patient already comprehended and has made a consent, medical action can be carried out. The consent of the medical action has two forms, namely:

a. Implied or assumed (implied consent), that is, the agreement provided by the patient implicitly without any express statement. This gesture is captured by the doctor from the attitude that is usually done by the patient. Generally the doctor's actions here are commonly known actions. For example, taking blood for laboratory tests, doing injections, doing treatment. Implied consent consists of normal circumstances and emergencies. 
b. Expressed consent, which is an agreement stated verbally or in writing if what is to be done is more than an examination procedure and ordinary action. Expressed consent, consisting of oral and written forms [16].

The consent given by the patient or his family after obtaining information from the doctor regarding medical actions to be carried out, in general in the form of filling and signing the consent form before medical action is taken on the patient. Doctor not only provide information before medical action is taken, but must also provide information during treatment.

Determining whether or not a medical action is quite difficult. Therefore, there are several elements that must be fulfilled by the doctors concerned. They are: 1) There is an action that is done or not done (neglect); 2) The action is carried out by a doctor or by a health worker under the guidance or supervision (nurse), even the action is carried out by providers of health care facilities, such as hospitals, pharmacies, clinics, etc.; 3) The actions taken must be in the form of medical actions, whether of diagnosis, provision of health therapy, or regarding hospital management; 4) The act is carried out on the patient; 5) The act is carried out by violating the applicable law, violating propriety, violating decency; violating existing professional principles; 6) Such actions are carried out with caution (negligence, carelessness, disregard for provisions, recklessness) or even intentionally; and 7) This action causes the patient to experience pain, injury, disability, damage to organs, and even death to the patient, besides that the patient also experiences material losses [16]. For this condition, then, the doctor or the parties concerned in handling the case in question, must be responsible for the consequences arising from his actions either administratively, civilly, or criminal.

\subsection{Criminal Liabilities for Malpractice}

In Indonesia, medical malpractice settlement cases refer to Article 66 of Law No. 29 of 2004 concerning Medical Practice, stipulating that:

a. "Anyone who knows or has an interest in being harmed by the actions of a doctor or dentist in carrying out medical practice can report in writing to the Chair of the Indonesian Medical Discipline Honorary Assembly".

b. "A complaint must at least contains;

- Complainant's identity;

- The name and address of the doctor or dentist's practice and the time of the action; as well as

- Reason for complaint".

c. "Complaints as referred to in paragraph (1) and paragraph (2) do not eliminate the right of every person to report suspected crimes to the competent authorities and/or sue for civil losses to the court"[17]."

In accordance with the sound of Article 66 of Law No. 29 of 2004 concerning Medical Practice, patients or families of patients who feel aggrieved from medical practices that are deemed inappropriate can complain about their cases through the Indonesian Medical Disciplinary Board, which is a non-litigation path. If the ethics violation is found in the examination, the Assembly concerned will forward the complaint to professional organizations such as the Indonesian Doctors Association or the Indonesian Dentist Association. These two assemblies are a professional judicial body tasked with prosecuting members of the profession itself.

In addition to the Council Code of Medical Ethics (hereinafter referred to MKEK), there are also institutions whose task is to discuss, examine, and make consideration to actions relating to violations of medical ethics, including; The Committee for Consideration and 
Development of Medical Ethics (P3EK) whose members consist of the Ministry of Health (DEPKES) and medical faculties, in addition to dentists, administrators of the Indonesian Medical Association (IDI), and the Indonesian Dentist Association (PDGI).

Each case regarding violation of the code of ethics shall be resolved by:

a. All issues concerning the violation of the code of ethics must first be reported to MKEK.

b. If the reported case is a case of pure code of ethics, the case shall be resolved by the Honorary Ethics Council of MKEK. However, if the case is not a case of a pure code of ethics or a case, it shall not be resolved by the MKEK, but it is forwarded to P3EK.

c. In the trial of MKEK or P3EK to make a decision, the member defense body of IDI can attend the trial if it is desired by the party concerned without the right to make a decision.

d. Problems related to the profession of doctors or dentists will be dealt with jointly by MKEK and the Dental Ethics Council (MKEKG).

e. For the sake of recording, each case of violation of the medical code of ethics and its resolution shall be reported to the Provincial P3EK [16].

However, it is not impossible if the victim or the victim's family wants to directly submit a report or submit the case through litigation. Given the composition of membership of the Honorary Council and Medical Ethics Development (P3EK), it seems very difficult to implement professional ethics firmly, because almost all who hold positions in the membership are basically doctors, dentists, or other health workers, where not one people from ordinary people are involved. In addition, law enforcement agencies only function as a place to consult and have absolutely no right to interfere in the issue of this code.

Speaking of forms of criminal liability for malpractice, there are a number of legal articles that can be imposed, namely as follows:

a. Uncovering the secret

Criminal acts in Article 322 of the Criminal Code paragraph (1) formulate as follows;

"Any person who with deliberate intent reveals a secret that he by reason of either his present or earlier office or profession is obliged to keep secret shall be punished with a maximum imprisonment of nine months or a maximum fine of six hundred rupiahs.".

In order for the actions listed above to be punished in the statement of Article 322 of the Criminal Code, it states that these actions must be able to fulfill the following elements:

- That which is revealed (uncovered) must be a secret.

- That person is obliged to keep the secret and he must really know that he is obliged to keep a secret.

- That the obligation to keep the secret is the result of a current position or job, as well as the one that he once held.

- Opening the secret is done intentionally.

Meanwhile, what is meant by a secret is something that is only known by the interested, while others do not know it yet, e.g. a doctor must keep the patient's illness secret.

b. Maltreatment (Mishandeling)

In the Indonesian Criminal Code the persecution is divided into 5 types, namely:

1. Standard Maltreatment or Maltreatment of basic forms (Article 351 of the Criminal Code), which are as follows;

- Maltreatment shall be punished with a maximum imprisonment of two years and eight months or a maximum fine of three hundred rupiahs.

- If the act results in a serious physical injury, the offender shall be punished with a maximum imprisonment of five years.

- If the fact results in death, he shall be punished by a maximum imprisonment of seven years. 
- With maltreatment shall be identified intentional injury to the health.

- Attempt to this crime shall not be punished.

2. Mild maltreatment contains Article 352 of the Criminal Code, which reads as follows;

- Except for the Articles 353 and 356 maltreatment that does not result in an illness or obstacle in the performance of official or professional activities, shall, as light maltreatment, be punished with a maximum imprisonment of three months or a maximum line of three hundred rupiahs. This sentence may be enhanced with one third in respect of the offender, who commits the crime against a person who is in service with him or who is his subordinate.

- Attempt to this crime shall not be punished.

3. Maltreatment committed in planned manner (Article 353 of the Criminal Code), namely:

- Maltreatment committed with premeditation shall be punished with a maximum imprisonment of four years.

- If the fact results in a serious physical injury, the offender shall be punished by a maximum imprisonment of seven years.

- If the fact results in death, he shall be punished by a maximum imprisonment of nine years.

4. Serious weight (Article 354 of the Criminal Code), namely as follows:

- The person who deliberately causes to another serious physical injury, shall, being guilty of serious maltreatment, be punished by a maximum imprisonment of eight years.

- If the fact results in death, the offender shall be punished by a maximum imprisonment of ten years.

5. Serious maltreatment committed in planned manner (Article 355 of the Criminal Code), as follows;

- Serious maltreatment committed with premeditation shall be punished by a maximum imprisonment of twelve years.

- If the fact results in death, the offender shall be punished with a maximum imprisonment of fifteen years.

Medical action is an action that is very helpful for the health of the nation. However, in its implementation it is not impossible for negligence resulting in casualties to occur frequently, especially as a result of unsystematic treatment and not carried out intensively by those who work as providers of medical services in the world of health. In addition, each country has its own rules that regulate provisions in all aspects and parts of people's lives, from individuals to groups. Health as an aspect of life that requires a very large amount cost must certainly obtain intensive and maximum treatment. Actually, health workers are indeed not figures who act perfectly in doing everything in the field of their professionalism, but lawless actions must have equal liability in order to create a fair atmosphere among the entire community; likewise the maltreatment that often occurs in health practices carried out by experts, such as doctors, there must be accountability both criminal and civil.

\section{Conclusion}

The following is a conclusion drawn based on the results of data analysis in this study. Malpractice in medical actions that are threatened and prohibited according to criminal law, 
namely (1) medical actions that occur as a result of negligence of health personnel in carrying out their obligations which results in patients experiencing serious injuries or even death; (2) a doctor's misdiagnosis in carrying out a thorough examination, which then results in errors in the administration of therapy and then which results in errors in the administration of drugs; (3) the act of committing violations or in contravention of existing medical procedures and standards, as well as taking medical actions but the capabilities they have are lacking or even inappropriate. The form of criminal liability for malpractice in Indonesia is various types according to their intensity.

The results of this study encourage the author to summarize a number of recommendations, i.e. that the Indonesian government is expected to immediately form a Law on Medical Malpractice that is separate from other laws as a complement to the Medical Practice Act. In addition, health workers, including doctors are advised to provide medical services to their patients based on existing procedures, be careful, and not reckless. In conditions that do not make it comfortable, patients or the community must have active participation by being creative in making treatment contracts with health workers by reading the rules that contain the conditions that can be done and should not be done for certain types of diseases. The study has limitations, namely discussing medical, medical actions in terms of the law as a result of negligence of health workers without examining the factors that affect the facilities and from the individual patients because medical failure can occur because of the patient's hesitation in expressing the suffering he experienced. Therefore, this topic can be the subject of further analysis.

\section{References}

[1] Roman, K, M.: Practice Policies: Potential Implications for Malpractice Litigation. J. Healthc. Risk Manag (1995)

[2] Knox, G, E.: High Reliability Perinatal Units : An Approach to the Prewention of Patient Injury and Medical Malpractice Claims. J. Healthc. Risk Manag (1999)

[3] Dooley, K.: current issues Supervisor Malpractice: Liability to the Supervisee in Clinical Supervision. vol. 38 (1999)

[4] Wissow, L, S.: Communication and malpractice claims - where are we now ?. Patient Educ. Couns. vol. 52. pp. 3-5 (2004)

[5] Lydiatt, D, D.: Medical malpractice and the thyroid gland. pp. 2002-2004 (2003)

[6] Stevenson, A, N, Iii, C, M, M, Shuler, M, D and Singer, P, S.: Complications and Legal Outcomes of Tonsillectomy Malpractice Claims. Am. Laryngol. Rhinol. Otol. Soc. Inc. vol. 122. pp. 71-74 (2012)

[7] Giancola, P, J.: Hospital Revisited: All use subject to JSTOR Terms and Conditions Casenote Proximate Cause in A Medical Malpractice Action : Hospital Revisited. Tort Insur. Law J. vol. 22 (2) pp. 324-330 (2016)

[8] Watkins, J, C.: Malpractice in Clinical Social Work: A Perspective on Civil Liability in the 1980's. vol. 1 (1). pp. 55-69 (1980)

[9] Gorney, M.: Office Staff Responsibilities in Preventing Surgery Malpractice. J. Healthc. Risk Manag (1991)

[10] www.sinarharapan.co.id.

[11] Lin, P, J.: Criminal judgments to medical malpractice in Taiwan. Leg. Med. vol. 11, pp. S376S378 (2009)

[12] Amiruddin and Asikin, Z.: Pengantar Metode Peneltian Hukum. Jakarta. Rajawali Pers (2010)

[13] Xu, X, Lori, J, R and Siefert, K, A.: Malpractice Liability Burden in Midwifery: A Survey of Michigan Certified Nurse-Midwives. J. Midwifery Women's Heal. vol. 53. pp. 19-27 (2008)

[14] West, J, C.: Case Law Update: Corporate, peer review information, medical malpractice, Good Samaritan statute, emergency medicine. Wiley Intersci. vol. 29 (1). pp. 44-51 (2009)

[15] Guwandi, J.: Dokter, Pasien, dan Hukum. Jakarta: Fakultas Kedokteran Universitas Indonesia 
(2003)

[16] Wiradharma, D.: Hukum Kedokteran. Jakarta. Binarupa Aksara (1996)

[17] Undang-Undang No. 29 Tahun 2004 Tentang Praktek Kedokteran. Lembaran Negara Republik Indonesia No. 298 (2014) 